\title{
Potencial antifúngico e antibacteriano de extratos vegetais da região de Divinópolis/MG
}

Extratos vegetais dos diferentes Biomas brasileiros têm sido utilizados como fármacos naturais no tratamento de variadas doenças. Atualmente, nos deparamos com um problema mundial de saúde pública: a resistência microbiana à fármacos tradicionalmente empregados. A maioria das plantas superiores possuem compostos com ação antimicrobiana que as protegem de microrganismos invasores. Neste contexto, o objetivo deste estudo foi avaliar o potencial antimicrobiano de extratos vegetais de espécies coletadas na região de Divinópolis/MG. Obteve-se extratos hidroetanólicos de partes aéreas dos espécimes avaliados. Foram testados extratos de Bidens subalternans, Anadhenantera columbrina, Annona mucosa, Eugenia dysenteryca, Inga vera, Tecoma stans e Crotalaria stipularia. Para os bioensaios foram empregados os testes Disco-Difusão em ágar e CIM/CBM. Utilizaram-se os microorganismos de referência Escherichia coli ATCC 29214 , Klebsiella pneumoniae ATCC43816, Enterobacter aerogenes ATCC 13048, Acinetobacter baumannii ATCC19606, Candida albicans ATCC18804 e Candida glabrata ATCC2001. Extratos de B. subalternans apresentaram efeito bactericida frente a E. coli e bacteriostático frente a A. baumanii e E. aerogenes. A. mucosa apresentou efeito bacteriostático frente a E. coli e E. dysenteryca e efeito bacterida frente a S. aureus. T. stans apresentou efeito bactericida frente a E. coli e bacteriostático em A. baumanii e E. aerogenes. Os extratos não apresentaram efeito antifúngico frente a C. albicans e C. glabrata. Os resultados obtidos neste estudo confirmam o grande potencial para o desenvolvimento de novos antimicrobianos baseados em extratos obtidos de partes aéreas de espécies vegetais da região de Divinópolis/MG.

Palavras-chave: Antimicrobiano; Cerrado; Extratos; Resistência.

\section{Antifungal and antibacterial potential of vegetable extracts of the Divinópolis/MG region}

\begin{abstract}
Plant extracts from different Brazilian biomes have been used as natural drugs without treatment of various diseases. We are currently faced with a worldwide public health problem: microbial resistance to drugs traditionally employed. Most of the higher plants have compounds with antimicrobial action for protection against invasive microorganisms. In this context, the objective of this study was evaluate the antimicrobial potential of plant extracts of species collected in the region of Divinópolis/MG. Hydroethanolic extracts were obtained from aerial parts of specimens. Bidens subalterns extracts, Anadhenantera columbrina, Annona mucosa, Eugenia dysenteryca, Inga vera, Tecoma stans and Crotalaria stipularia were tested. For the bioassays with the tests the Disc-Diffusion tests in agar and CIM/CBM. Was used the following reference microorganisms: Escherichia coli ATCC 29214, Klebsiella pneumoniae ATCC43816, Enterobacter aerogenes ATCC 13048, Acinetobacter baumannii ATCC19606, Candida albicans ATCC18804 and Candida glabrata ATCC2001. B. subalterns extracts presented bactericidal effect against $E$. coli and bacteriostatic against $A$. baumanii and $E$. aerogenes. A. mucosa presented bacteriostatic effect against $E$. coli and $E$. dysenteryca bacterial effect against $\mathrm{S}$. aureus. T. stans presented bactericidal effect against $\mathrm{E}$. coli and bacteriostatic in A. baumanii and E. aerogenes. The extracts showed no antifungal effect against C. albicans and C. glabrata. The results obtained in this study confirm the great potential for the development of new antimicrobials based on extracts obtained from aerial parts of vegetables from the region of Divinópolis/MG.
\end{abstract}

Keywords: Antimicrobial; Cerrado; Extracts; Resistence.

Topic: Microbiologia Agrícola e Ambiental

Reviewed anonymously in the process of blind peer.

Thaís Paula Rodrigues Gonçalves (id

Universidade do Estado de Minas Gerais, Brasil

http://lattes.cnpq.br/9933053067057014

http://orcid.org/0000-0001-8409-5956

thaispaula.rgs@outlook.com

\section{Adriano Guimaraes Parreira (ic}

Universidade do Estado de Minas Gerais, Brasil

http://lattes.cnpq.br/1803178442452988

http://orcid.org/0000-0002-7770-7165

aguiparreira@ufsj.edu.br

William Gustavo de Lima (iD

Universidade Federal de São João Del-Rei, Brasil

http://lattes.cnpq.br/8460786238043708

http://orcid.org/0000-0001-8946-9363

williamgustavofarmacia@hotmail.com

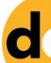

DOI: 10.6008/CBPC2179-6858.2018.003.0003
Received: 10/02/2018

Approved: 24/03/2018

Mairon César Coimbra (iD)

Universidade Federal de São João Del-Rei, Brasil

http://lattes.cnpq.br/9064803050046162

http://orcid.org/0000-0002-0496-5139

coimbra@ufsj.edu.br

Referencing this:

GONÇALVES, T. P. R.; PARREIRA, A. G.; LIMA, W. G.; COIMBRA, M. C. Potencial antifúngico e antibacteriano de extratos vegetais da região de Divinópolis/MG. Revista Ibero Americana de Ciências Ambientais v.9, n.3, p.25-37, 2018. DOI: http://doi.org/10.6008/CBPC21796858.2018 .003 .0003 


\section{INTRODUÇÃO}

O conhecimento sobre o potencial terapêutico de plantas nativas e exóticas proporciona a valorização das espécies por estimular sua preservação, desenvolvimento sustentável e a produção econômica como instrumentos para o fortalecimento e desenvolvimento de comunidades rurais e tradicionais, bem como aspectos relacionados a mercados locais, nacionais ou internacionais (CABRAL, 2000). Tal valorização também proporciona a prática interdisciplinar de Educação Ambiental, sendo as plantas eficientes instrumentos pedagógicos, além de oferecem oportunidades de inserção de diferentes aspectos, como por exemplo conservação do Cerrado e Mata atlântica, hortas medicinais escolares e a importância da manutenção de quintais em áreas urbanas (GUARIM NETO,2006).

Substâncias extraídas de variadas espécies vegetais, típicas dos diferentes Biomas brasileiros, tais como Cerrado, Floresta Amazônica e Mata Atlântica, têm sido utilizados como fármacos naturais pelas populações locais no tratamento de diferentes doenças (FRANCA, 2008). Segundo estudo de Ming e colaboradores (2012), no Bioma Mata Atlântica concentram-se importante relação de plantas com efeitos medicinais publicadas na resolução divulgada pela Anvisa (2010). O uso de plantas medicinais no país com a finalidade de tratar enfermidades foi sempre expressivo, principalmente devido à extensa e diversificada flora (HALBERSTEIN, 2005). Embora sejam bastante empregadas, ainda são poucas as evidências científicas comprovando a eficácia do potencial medicinal de espécies vegetais no Brasil (LIMA et al., 2006). Estudos relacionados a identificação do potencial bioativo de plantas nativas são de extrema importância, pois além de tratar enfermidades contribuem para a preservação e cultivo da espécie.

De acordo com projeções do Instituto Brasileiro de Plantas Medicinais (IBPM), o mercado de medicamentos fitoterápicos movimenta cerca de 500 milhões de dólares por ano no Brasil, enquanto no mundo sejam gastos cerca de US\$ 27 bilhões (aproximadamente 7\% do mercado mundial de medicamentos) com plantas medicinais. O mercado farmacêutico tradicional cresce, mundialmente, de $3 \%$ a $4 \%$ ao ano, enquanto o de fitoterápicos sobe de 6\% a 7\% (BOTSARIS, 2010). Tal fato pode ser explicado pelo avanço das doenças infecciosas com elevados índices de morbidade e mortalidade, estimulando as indústrias farmacêuticas para o desenvolvimento de novas drogas antimicrobianas, especialmente em função do aumento de registros de resistência aos antimicrobianos tradicionais.

O aparecimento de resistência a drogas antimicrobianas é um dos grandes desafios dos sistemas de saúde mundiais. Anualmente, morrem cerca de 700.000 pessoas por infecções causadas por bactérias multirresistentes no mundo (WHO, 2014). Estudos recentes revelaram que, caso nenhuma medida efetiva seja tomada pelos órgãos de vigilância sanitária dos diferentes países, em 2050 bactérias multirresistentes matarão 1 pessoa a cada 3 segundos no mundo, totalizando 10 milhões de mortes anuais, superando doenças crônicas como o câncer e o diabetes (O’NEILL, 2016). No Brasil, o panorama também é muito preocupante. O Ministério da Saúde estima que das 720.000 infecções hospitalares que ocorrem anualmente no país (BARROS et al., 2012), mais de 70\% envolvem bactérias que são resistentes a pelo menos um dos antimicrobianos comumente utilizados para o tratamento desses pacientes. $\mathrm{O}$ custo hospitalar atribuível à 
ocorrência dessas infecções é de US\$ 651 por dia, elevando-se para US\$ 1.780 em UTIs, o que contribui para a elevação expressiva dos custos em saúde pública no país (SANCHEZ-VELAZQUEZ et al., 2006). São frequentes os relatos sobre isolamentos de bactérias que eram reconhecidamente sensíveis às drogas de uso na rotina, mas que se tornaram resistentes a todos ou a quase todos fármacos disponíveis no mercado (SAKAGAMI et al., 2006). Dessa forma, a Organização Mundial de Saúde (OMS) passou a incentivar o uso da fitoterapia (BRASIL,2006), ou seja, medicamentos à base de plantas medicinais, nos quais os compostos vegetais têm atividade biológica como estratégia alternativa de controle. Assim faz-se necessário a busca por atividade antimicrobiana nas inúmeras espécies vegetais utilizadas na medicina tradicional (SIMÕES et al., 1998; AURICCHIO et al., 2003).

No Brasil, estudos sobre antimicrobianos de origem vegetal obtiveram impulso a partir dos trabalhos de Lima (1959) e de Santana e colaboradores (1968), os quais relataram propriedades antimicrobianas e antitumorais de extratos de plantas nativas. As plantas contém inúmeros constituintes, provenientes do metabolismos secundário, que podem apresentar efeitos terapêuticos devido à ação sinérgica ou isolada destas substâncias por apresentarem uma complexa organização estrutural que favorecem inúmeros processos fisiológicos. Geralmente, os mecanismos de ação de produtos naturais frente a bactérias estão envolvidos em desintegração da membrana citoplasmática, desestabilização da força próton motriz (FPM), fluxo de elétrons, transporte ativo e coagulação do conteúdo da célula. Nem todos os mecanismos de ação agem em alvos específicos, podendo alguns sítios serem afetados em conseqüência de outros mecanismos (BURT, 2004).

A maioria das plantas superiores possuem compostos que atuam como antimicrobianos naturais e as protegem de microrganismos invasores (SCHELZ et al., 2006). As substâncias com ação bactericida presentes nas plantas são detectadas pela observação do crescimento de microrganismos colocados em contato com tecidos ou extratos destes vegetais. Para detectar tais substancias são empregados variados métodos que se diferenciam na sensibilidade ou em seus princípios. Os resultados obtidos são influenciados pelo método escolhido, assim como pelos microrganismos empregados nos testes. A parte da planta utilizada também interfere nos resultados bem como a forma de uso: suco, extrato (extração aquosa ou por solvente orgânico) ou ainda óleo essencial (SIMÕES et al., 2000).

Com base nestas considerações, o objetivo deste trabalho foi o de avaliar o potencial antimicrobiano e antifúngico de extratos vegetais de espécimes obtidas do Cerrado e fragmentos de Mata Atlântica da região de Divinópolis MG, com destaque para aquelas com relatos de uso na medicina popular regional.

\section{MATERIAIS E MÉTODOS}

\section{Coleta e preparo de extratos}

Os espécimes vegetais foram coletados no município de Divinópolis/MG, sendo identificados e os exemplares depositados no herbário da empresa de Pesquisa e Agropecuária de Minas Gerais (EPAMIG/PAMG). Foram analisadas 7 espécies típicas de Cerrado e Mata Atlântica, usando como método de 
busca espécies de famílias com relatos de propriedades terapêuticas descritos na literatura e cujas descrições, bem como sua Geolocalização, são apresentadas na Tabela 1.

Tabela 1: Apresentação das espécies vegetais, famílias, partes coletadas e localização da coleta.

\begin{tabular}{|l|l|l|l|l|}
\hline Espécie Vegetal/ No registro exsicata & Família & Nome popular & $\begin{array}{l}\text { Órgão } \\
\text { coletado }\end{array}$ & Geolocalização \\
\hline Bidens subalternans DC. PAMG 57686 & Asteraceae & Picão-preto & Folhas & $\begin{array}{l}20^{\circ} 66^{\prime} 38.459 " \mathrm{~S} \\
44^{\prime} 50^{\prime} 47.184^{\prime \prime} \mathrm{W}\end{array}$ \\
\hline $\begin{array}{l}\text { Tecoma stans (L.) Juss. Ex Kunth PAMG } \\
\mathbf{5 8 2 8 4}\end{array}$ & Bignoneaceae & Amarelinho & Folhas e Flores & $20^{\circ} 10^{\prime} 19.7^{\prime \prime} \mathrm{S} 44^{\circ} 53^{\prime} 43.3 \mathrm{~W}$. \\
\hline $\begin{array}{l}\text { Eugenia dysenterica DC } \\
\text { PAMG 56415 }\end{array}$ & Myrtaceae & Cagaitera & Folhas & $\begin{array}{l}20^{\circ} 10^{\prime} 19.088^{\prime \prime} \mathrm{S} \\
44^{\prime} 53^{\prime} 41.73^{\prime \prime} \mathrm{W}\end{array}$ \\
\hline $\begin{array}{l}\text { Crotalaria stipularia Desv. } \\
\text { PAMG 57643 }\end{array}$ & Fabaceae & Xique-xique & Folhas & $\begin{array}{l}20^{\circ} 6^{\prime} 38.459^{\prime \prime} \mathrm{S} \\
44^{\circ} 50^{\prime} 47.184^{\prime \prime} \mathrm{W}\end{array}$ \\
\hline $\begin{array}{l}\text { Annona mucosa Jacq. } \\
\text { PAMG 58285 }\end{array}$ & Annonaceae & $\begin{array}{l}\text { Fruta-do- } \\
\text { conde }\end{array}$ & Folhas & $\begin{array}{l}20^{\circ} 10^{\prime} 19.088^{\prime \prime} \mathrm{S} \\
44^{\circ} 53^{\prime} 41.73^{\prime \prime} \mathrm{W}\end{array}$ \\
\hline $\begin{array}{l}\text { Inga vera subsp. affinis (DC.) T.D. Penn. } \\
\text { PAMG 56398 }\end{array}$ & Fabaceae & Ingá & Folhas & $20^{\circ} 10^{\prime} 18.4^{\prime \prime} \mathrm{S} 44^{\circ} 53^{\prime} 39.6^{\prime \prime} \mathrm{W}$ \\
\hline $\begin{array}{l}\text { Anadenanthera columbrina (Vell.) Brenan } \\
\text { PAMG 57682 }\end{array}$ & Fabaceae & Angico-Branco & Folhas & $\begin{array}{l}20^{\circ} 66^{\prime} 38.459^{\prime \prime} \mathrm{S} \\
44^{\prime} 50^{\prime} 47.184^{\prime \prime} \mathrm{W}\end{array}$ \\
\hline
\end{tabular}

Para a obtenção dos extratos dos espécimes coletados, o material vegetal coletado foi submetido à secagem em estufa com circulação de ar forçada à 40 ำ, por 7 dias. Após a secagem, o material foi triturado em moinho de facas (Factos, MA 048). O material fragmentado/pulverizado foi extraído em etanol 70\% (1:9) (p:v) através do método de turbólise por 5 minutos a 3.000 rpm, utilizando-se de equipamento Ultra-Turvax (modelo MA-102 PLUS) (Figura 1). O extrato obtido foi filtrado e armazenado em congelador por 48h (Figura 2). Depois, procedeu-se a evaporação do solvente presente no filtrado em evaporador rotativo e então liofilizado em Liofilizador marca Liotop (Liobras- K105) a -95C para obtenção de um pó fino como produto final (Figuras 3 e 4 ).
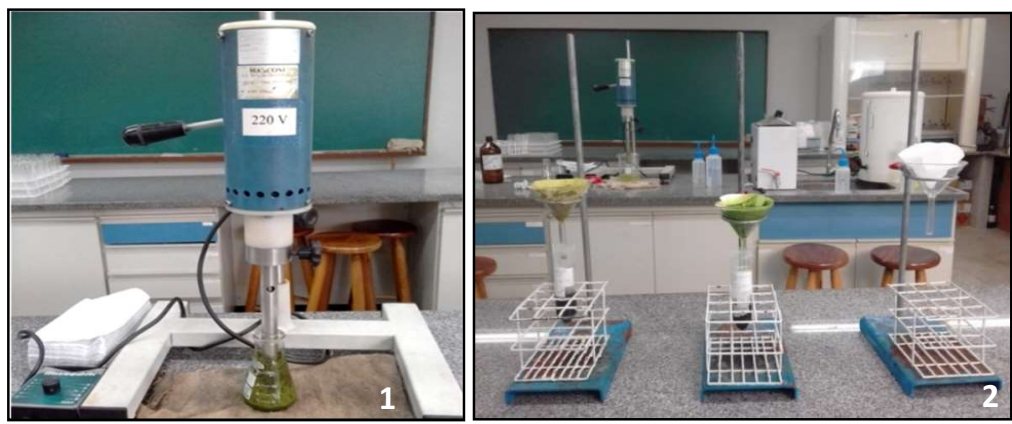

Figuras 1 e 2: (1) Etapa de obtenção dos extratos hidroetanólicos empregando Ultra-Turrax. (2) Ilustração da etapa de filtragem dos extratos hidroetanólicos em papel de filtro.
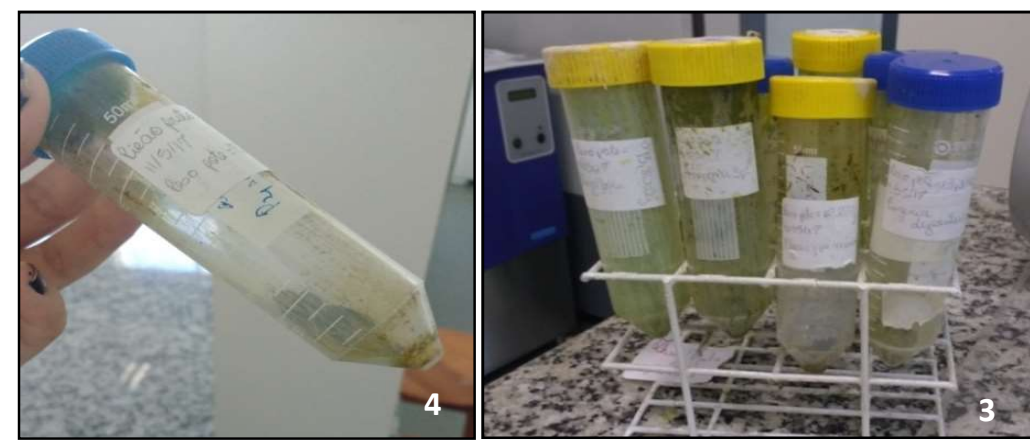

Figuras 3 e 4: Aspecto geral do material obtido após etapa de liofilização. 


\section{Ensaios de atividades antimicrobianas e antifúngicas}

Para a avaliação do efeito antibacteriano e antifúngico os extratos foram inicialmente triados empregando-se o teste qualitativo de disco-difusão em meio ágar-MH segundo o documento M2-A8 do Clinical \& Laboratory Standards Institute (CLSI, 2012). Posteriormente, para os extratos que apresentaram halos de inibição compatíveis com atividade antimicrobiana na triagem, foi determinada a concentração inibitória mínima (CIM) utilizando-se do método de microdiluição em caldo, segundo os documentos M07A9 antibacteriano (CLSI, 2012) e M27-A2 antifúngico (NCCLS, 2002) do CLSI (2012). As espécies de microrganismos selecionadas seguiram critério clínico e epidemiológico baseado nos patógenos bacterianos e fúngicos mais frequentemente isolados em infecções clínicas, como também de maior relevância no desenvolvimento e disseminação de determinantes de resistência aos antimicrobianos.

\section{Microrganismos}

Os microrganismos empregados neste estudo são originários do American Type Culture Colection (ATCC), cedidos pelo laboratório de referência de Microrganismos da Fundação Oswaldo Cruz (FIOCRUZ, Rio de Janeiro, Brasil). Os testes de atividade antibacteriana foram conduzidos utilizando-se 6 espécies, sendo uma Gram-positiva: Staphylococcus aureus ATCC 25923; 3 Gram-negativas fermentadoras (Enterobacteriaceae): Escherichia coli ATCC 29214, Klebsiella pneumoniae ATCC43816 e Enterobacter aerogenes ATCC 13048 e 1 Gram-negativa não fermentadora: Acinetobacter baumannii ATCC19606. Nos ensaios antifúngicos, por sua vez, foram empregadas duas espécies do gênero Candida, C. Albicans ATCC18804 e C. glabrata ATCC2001. Todas as espécies de bactérias e leveduras foram estocadas a $-80^{\circ} \mathrm{C}$ em caldo nutriente e caldo Sabouraud-dextrose (Acumedia ${ }^{\circledR}$, Brazil) glicerinados (25\%), respectivamente, até o uso.

\section{Avaliação da Concentração Inibitória Mínima (CIM)}

A determinação da atividade antimicrobiana por meio da Concentração Inibitória Mínima (CIM) foi avaliada pelo método de microdiluição em caldo, descrito nos protocolos M07-A9 (para o ensaio antibacteriano) e M27-A2 (para o ensaio antifúngico) (CLSI,2012 e NCCLS, 2002), Figura 5. Os extratos foram dissolvidos em água e em DMSO na proporção 10:1 e empregados na faixa de concentração de 2-0,003 $\mathrm{mg} \cdot \mathrm{mL}^{-1}$ durante os ensaios.

Para o preparo do inoculo bacteriano, colônias isoladas de uma estria composta de $24 \mathrm{~h}$ de crescimento foram transferidas para tubos contendo solução salina $0.85 \%(p / v)$ tamponada. A turvação da salina foi ajustada espectrofotometricamente a $625 \mathrm{~nm}$ equivalente a escala 0,5 de McFarland, o que representa uma densidade bacteriana aproximada de $1,5 \times 10^{8} \mathrm{UFC} / \mathrm{mL}$. A seguir, uma alíquota de $50 \mu \mathrm{L}$ desse pré-inóculo foi transferida para $10 \mathrm{~mL}$ de caldo Mueller-Hinton $(\mathrm{MH})$, obtendo-se uma suspensão contendo aproximadamente $1,5 \times 10^{6} \mathrm{UFC} / \mathrm{mL}$, o qual foi empregado na montagem das microplacas. A suspensão fúngica foi preparada de modo semelhante. Estrias de $48 \mathrm{~h}$ foram utilizadas na obtenção da suspensão em 
salina, que ao ser ajustada para a escala 0,5 de McFarland $\left(\mathrm{DO}_{525 \mathrm{~nm}}=0,2\right)$, representando densidade celular de aproximadamente $1 \times 10^{6} \mathrm{UFC} / \mathrm{mL}$. Para a obtenção do inóculo final foram realizadas duas diluições, produzidas pela transferência de $20 \mu \mathrm{L}$ do pré-inóculo para $980 \mu \mathrm{L}$ de caldo Sabouraud-dextrose (SD) (diluição 1:50) e posteriormente de $1 \mathrm{~mL}$ da suspensão resultante para $19 \mathrm{~mL}$ de caldo SD (diluição 1:20), obtendo-se assim uma suspensão de trabalho com $1 \times 10^{3} \mathrm{UFC} / \mathrm{mL}$.

Para a obtenção da CIM foram empregadas microplacas de poliestireno de 96 poços (figura 5). No controle positivo utilizou-se caldo $\mathrm{MH}$ e o inoculo microbiano; o controle negativo foi determinante para a garantia da ação inibitória do diluente; para o controle de esterilidade empregou-se caldo $\mathrm{MH}$ e os antibióticos comerciais cloranfenicol e amoxicilina. Foi também empregado o antifúngico cetoconazol para controle. Por fim, as placas foram incubadas em estufa bacteriológica a 37 으 por $24 \mathrm{~h}$ para as bactérias e a 28ํㅡ por $48 \mathrm{~h}$ para as leveduras. A CIM foi determinada como a menor concentração onde não se observava crescimento microbiano a olho nu. Os ensaios foram realizados em triplicata nos poços das placas, com três replicatas independentes entre elas.

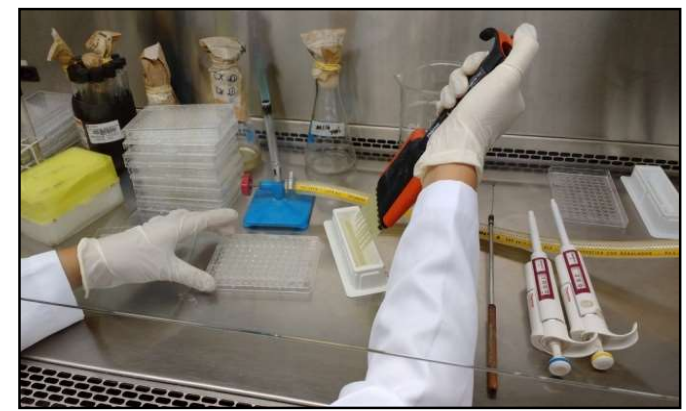

Figura 5: Ilustração do processo de microdiluição em placas de 96 poços.

\section{Avaliação das Concentrações Bactericida Mínima (CBM)}

O efeito bactericida dos extratos foi avaliado pela determinação da CBM, segundo metodologia descrita por Lyu e colaboradores (2017), com algumas modificações. Um total de $10 \mu \mathrm{L}$ dos poços sem crescimento no ensaio de MIC foram aliquotados e transferidos para uma placa contendo meio ágar MuellerHinton. O material foi semeado pela técnica de spread plate e em seguida as placas foram incubadas a 37으 por $24 \mathrm{~h}$ para a avaliação do efeito sobre bactérias e a $28{ }^{\circ} \mathrm{C}$ por $48 \mathrm{~h}$ com vistas a avaliar o efeito sobre os fungos. Em seguida, considerou-se como ação bacteriostática positiva o extrato que inibiu o crescimento dos microrganismos na CIM, mas que houve crescimento na subcultura, e ação bactericida o extrato vegetal que inibiu o crescimento na CIM e que apresentou crescimento de até 3 colônias com morfologias compatível a espécie estudada na superfície do ágar (ROCHA et al., 2013). Os experimentos foram repetidos de 2 a 3 vezes para confirmação e comparação dos resultados.

\section{Teste Qualitativo Disco-Difusão em Ágar}

Empregou-se o teste de difusão em ágar como método qualitativo, descrito por Bauer et al. (1966). O protocolo completo encontra-se em "Performance Standards for Antimicrobial Disk Susceptibility Tests" (CLSI, 2012). Discos de papel de filtro estéreis de $6 \mathrm{~mm}$ de diâmetro foram saturados com os extratos vegetais 
hidroetanólicos obtidos. Após a absorção dos extratos, os discos foram colocados em microtubos de 1,5 a 2 $\mathrm{ml}$ e levados à estufa a $60^{\circ} \mathrm{C}$ para secagem por um período de $24 \mathrm{~h}$ (Figura 7). Em seguida, foram refrigerados à temperatura de $10^{\circ} \mathrm{C}$ para posterior utilização.

O inóculo foi preparado em caldo Muller-Hinton com turvação equivalente a 0,5 da escala de MacFarland, correspondendo a aproximadamente de 1 a $2 \times 10^{8} \mathrm{UFC} / \mathrm{mL}$, medidas em espectrofotômetro a $625 \mathrm{~nm}$. A suspensão foi semeada com Swabs de algodão sobre as placas de Petri que continham aproximadamente $15 \mathrm{~mL}$ de meio ágar-nutriente, em espessura aproximada de $4 \mathrm{~mm}$ (SHADOMY et al., 1980). Após 5 min para a absorção do inóculo foram dispensados os discos, comprimindo-os gentilmente contra a superfície do meio de cultura em placa de petri já com as bactérias semeadas (Figura 6). Foram também embebidos discos com os antibióticos cefalexina e ciprofoxacina e o antifúngico cetoconazol, empregados como controle. Cada experimento foi repetido entre 3 a 4 vezes para confirmação e comparação de resultados. Após $24 \mathrm{~h}$ de incubação das placas de Petri em estufa a $370 \mathrm{C}$ foi realizada a avaliação dos resultados com base na medição do diâmetro dos halos de inibição formados, empregando-se régua milimetrada. Os resultados foram expressos em termos do diâmetro do halo de inibição formado, sendo padronizado: < $9 \mathrm{~mm}$ [ausência de susceptibilidade (R)]; de $9 \mathrm{~mm}$ a $12 \mathrm{~mm}$ [intermediário (I)]; >12 mm [susceptibilidade (S)] conforme experimentos realizados por Alves et al. (2000).

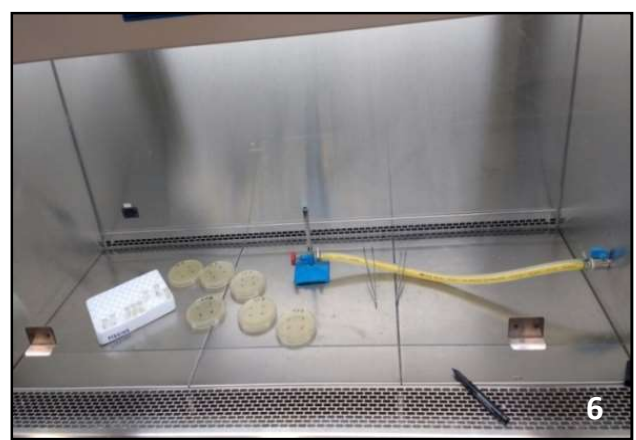

Figura 6: Ilustração da etapa de inoculação nas placas com os discos na superfície do meio sólido.

\section{RESULTADOS}

De um total de 7 espécies vegetais e 8 extratos avaliados, considerando-se que para $T$. stans foram estudados extratos de flores e folhas, um total de 4 espécies indicaram presença de compostos com atividade antimicrobiana em seus extratos. São elas, extratos das folhas de B. subalternans, E. dysenterica e A. mucosa e extratos de flores de $T$. stans. Os extratos de B. subalternans, E. dysenterica e flores de $T$. stans apresentaram efeitos bactericidas para algumas das bactérias testadas. A. mucosa apresentou efeito bacteriostático, conforme mostrado na Tabela 2. Com os resultados do teste qualitativo disco-difusão podese confirmar e comparar o resultado obtido pelo CIM/CBM (Tabela 3). Extratos de C. stipularia, I. vera e A. columbrina não demonstraram efeitos antimicrobianos, bem como ausência de inibição de crescimento frente as espécies de microorganismos e leveduras avaliadas. Para as leveduras testadas não foi notada atividade antifúngica em nenhum dos extratos vegetais avaliados. 
Tabela 2: Valores de CIM/CBM em $\mathrm{mg} \mathrm{mL}^{-1}$ dos extratos de partes das plantas avaliadas frente as cepas de microrganismos testadas.

\begin{tabular}{|l|l|l|l|l|l|l|l|}
\hline Espécies Vegetais & E.c & S.a & K.p & A.b & E.a & C.a & C.g \\
\hline B. subalternans & $\mathbf{1 ( 2 )}$ & $>2(-)$ & $>2(-)$ & $\mathbf{2 ( > 2 )}$ & $\mathbf{2 ( > 2 )}$ & $>2(-)$ & $>2(-)$ \\
\hline T. stans (flores) & $\mathbf{0 , 5 ( 1 )}$ & $>2(-)$ & $>2(-)$ & $\mathbf{2}(>\mathbf{2})$ & $\mathbf{2 ( > 2 )}$ & $>2(-)$ & $>2(-)$ \\
\hline T. stans (folhas) & $>2(-)$ & $>2(-)$ & $>2(-)$ & $>2(-)$ & $>2(-)$ & $>2(-)$ & $>2(-)$ \\
\hline A. columbrina & $>2(-)$ & $>2(-)$ & $>2(-)$ & $>2(-)$ & $>2(-)$ & $>2(-)$ & $>2(-)$ \\
\hline E. dysenterica & $>2(-)$ & $\mathbf{2 ( 2 )}$ & $>2(-)$ & $>2(-)$ & $>2(-)$ & $>2(-)$ & $>2(-)$ \\
\hline A. mucosa & $>2(-)$ & $>2(-)$ & $>2(-)$ & $\mathbf{2 ( > 2 )}$ & $>2(-)$ & $>2(-)$ & $>2(-)$ \\
\hline I. vera & $>2(-)$ & $>2(-)$ & $>2(-)$ & $>2(-)$ & $>2(-)$ & $>2(-)$ & $>2(-)$ \\
\hline C. stipularia & $>2(-)$ & $>2(-)$ & $>2(-)$ & $>2(-)$ & $>2(-)$ & $>2(-)$ & $>2(-)$ \\
\hline
\end{tabular}

Atividade antimicrobiana de 8 extratos hidroetanólicos frente a 7 microrganismos de referência (ATCC).E.c=Escherichia coli, S.a=Staphylococcus aureus, K.p=Klebsiella pneumoniae, A.b=Acinetobacter baumannii. E.a=Enterobacter aerogenes, C.a=Candida albicans, C.g=Candida glabrata (-) =não houve inibição.

Tabela 3: Médias \pm desvio padrão dos resultados para o teste Disco-Difusão, dos 8 extratos hidroetanólicos obtidos das plantas coletadas em Divinópolis, MG frente a 7 microrganismos de referência.

\begin{tabular}{|l|l|l|l|l|l|l|l|}
\hline Espécie Vegetal & $\mathrm{E} . \mathrm{c}$ & $\mathrm{S} . \mathrm{a}$ & $\mathrm{K} . \mathrm{p}$ & $\mathrm{A} . \mathrm{b}$ & $\mathrm{E} . \mathrm{a}$ & C.a & C.g \\
\hline B.subalternans & $\mathrm{S} .27,3 \pm 1,2$ & $\mathrm{R}$ & $\mathrm{R}$ & $\mathrm{S} .12,7 \pm 1,5$ & $\mathrm{~S} .24,6 \pm 0,3$ & $\mathrm{R}$ & $\mathrm{R}$ \\
\hline T.stans (flores) & $\mathrm{S} .23,6 \pm 0,9$ & $\mathrm{R}$ & $\mathrm{R}$ & $\mathrm{S} .13,3 \pm 0,9$ & $\mathrm{~S} .21 \pm 0,6$ & $\mathrm{R}$ & $\mathrm{R}$ \\
\hline T.stans (folhas) & $\mathrm{I} .10 \pm 4,2$ & $\mathrm{R}$ & $\mathrm{R}$ & $\mathrm{R}$ & $\mathrm{R}$ & $\mathrm{R}$ & $\mathrm{R}$ \\
\hline A. columbrina & $\mathrm{R}$ & $\mathrm{R}$ & $\mathrm{R}$ & $\mathrm{R}$ & $\mathrm{R}$ & $\mathrm{R}$ & $\mathrm{R}$ \\
\hline E. dysenterica & $\mathrm{I} .11,3 \pm 0,7$ & $\mathrm{~S} .15 \pm 0,6$ & $\mathrm{R}$ & $\mathrm{R}$ & $\mathrm{R}$ & $\mathrm{R}$ & $\mathrm{R}$ \\
\hline A. squamosa & $\mathrm{I} .10 \pm 3,4$ & $\mathrm{R}$ & $\mathrm{R}$ & $\mathrm{R}$ & $\mathrm{R}$ & $\mathrm{R}$ & $\mathrm{R}$ \\
\hline I.vera & $\mathrm{R}$ & $\mathrm{R}$ & $\mathrm{R}$ & $\mathrm{R}$ & $\mathrm{R}$ & $\mathrm{R}$ & $\mathrm{R}$ \\
\hline C. stipularia & $\mathrm{R}$ & $\mathrm{R}$ & $\mathrm{R}$ & $\mathrm{R}$ & $\mathrm{R}$ & $\mathrm{R}$ & $\mathrm{R}$ \\
\hline
\end{tabular}

Atividade antimicrobiana de 8 extratos hidroalcoólicos frente a 7 microrganismos de referência (ATCC). E.c=Escherichia coli, S. $a=$ Staphylococcus aureus, K.p=Klebsiella pneumoniae,A. $b=$ Acinetobacter baumannii, E.a= Enterobacter aerogenes, C.a=Candida albicans, C.g= Candida glabrata.R=resistente (não houve desenvolvimento do halo de inibição), I=intermediário (houve fraco desenvolvimento do halo de inibição entre 9 e $12 \mathrm{~mm}$ ), S=sensível (houve desenvolvimento do halo de inibição maior que $12 \mathrm{~mm}$ ).

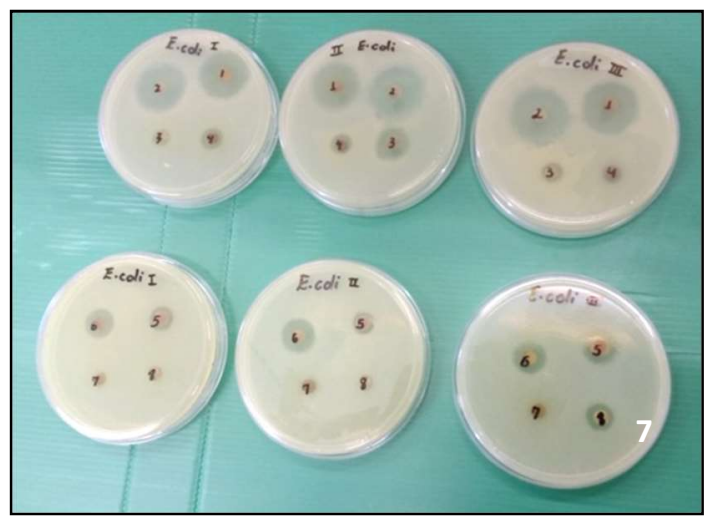

Figura 7: Teste de disco-difusão em ágar-nutriente evidenciando halos de inibição dos extratos frente a bactéria Gram-negativa Escherichia coli. 1- B. subalternans, 2- Flores de T. stans, 3- Folhas de T. stans, 4- A. colubrina 5- E. dysenterica, 6- A. mucosa, 7- I. vera, 8- C. stipularia.

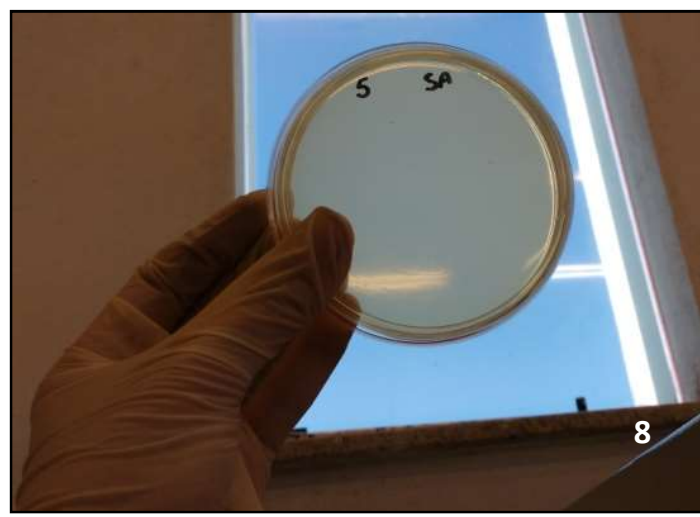

Figura 8: Resultado do CIM após realização do CBM, demonstrando atividade bactericida de $E$. dysenterica sobre $S$. aureus. 


\section{DISCUSSÃO}

Em estudos de Couto e colaboradores (2009), em que determinaram a caracterização físico-química do pó das folhas de E. dysenterica, notou-se alto teor de taninos e flavonóides, uma vez que estes totalizaram 53,7 e 3,45\%, respectivamente, dos compostos fenólicos encontrados, o que poderia justificar o potencial terapêutico antimicrobiano dessa espécie, uma vez que compostos fenólicos, como taninos e flavonoides, são os responsáveis pelas atividades farmacológicas dos produtos naturais. Tal fato também se relaciona aos resultados encontrados com o emprego dos extratos vegetais daquela espécie no presente estudo.

Krinski e colaboradores (2014) analisaram o potencial inseticida de espécies de plantas da família Annonaceae demonstrando que as plantas desta família estão ganhando destaque como biopesticidas, por serem naturalmente bioativas, apresentando atividade citotóxica, antitumoral, vermicida, antimicrobiana, imunossupressora, antiemética, antimalárica e também inseticida. Tal fato corrobora com os achados no presente estudo para extratos de A. mucosa, que demonstraram atividade bacteriostática.

Atualmente, há inúmeros relatos sobre potencial antimicrobiano e antifúngico de vegetais diversos, com histórico medicinal ou não, dentre eles destaca-se a família Bignoneaceae, na qual se enquadra a espécie Tecoma stans aqui analisada. O potencial medicinal das Bignoniáceas é estudado desde 1880, quando foram relatados estudos sobre suas ações terapêuticas. Em 1882 foi descoberto na espécie Tabebuia avellanedae a substância denominada lapachol, que possui variadas propriedades farmacológicas, tais como analgésicas e antitumorais e, atualmente, essa substância tem sido sintetizada a fim de aproveitarem suas propriedades já descritas (FONSECA, 2003). Estudos mais recentes demonstraram o potencial antimicrobiano de Tabebuia alba, cujo extrato etanólico obtido de suas flores demonstraram ação bactericida frente a Staphylococcus epidermidis, enquanto o extrato etanólico da folha foi moderadamente ativo com efeito bacteriostático sobre S. epidermidis e S. aureus (SANTOS et al., 2015). Tais fatores tornam a atividade bactericida descoberta nos extratos de Tecoma stans justificáveis.

As plantas da família Astereaceae apresentam compostos químicos variados, tais como poliacetilenos, lactonas sesquiterpênicas, óleos essenciais voláteis terpenóides, monoterpenosvoláteis, alcalóides, látex com triterpenos, saponinas, triterpenóides e flavonóides (MARKHAM, 1982). Tal composição sugere a presença destes compostos bioativos na espécie $B$. subalternans, devido sobretudo a seu potencial antibacteriano aqui encontrado. Deba e colaboradores (2008) mostraram que os óleos essenciais de folhas e flores de Bidens pilosa, espécie do mesmo gênero de B. subalternans, apresentavam significativa bioatividade, medida por halos de inibição em placas de ágar contra seis espécies de bactérias (Micrococcus flavus, Bacillus subtilis, Bacillus cereus, Bacillus pumilus, Escherichia coli e Pseudomonas ovalis). Extratos de folhas (RABE et al., 1997; DEBA et al., 2008), das flores (DEBA et al., 2008) da planta inteira (KHAN et al., 2001) e das raízes (ASHAFA et al., 2009) também mostraram atividade antimicrobiana em variados relatos encontrados na literatura.

A. colubrina, I. vera e C. stipularia são espécies pertencentes à família Fabaceae, na qual umas grandes variedades de metabólitos secundários são produzidas por membros daquela família, tais como 
alcaloides, aminoácidos não proteicos, aminas, fenilpropanoides, flavonoides, isoflavonoides, compostos fenólicos, esteroides e ésteres de ácido graxo (IGNOATO, 2012). Tais compostos são os principais responsáveis por diversas atividades biológicas dos vegetais. São inúmeros os estudos referentes ao potencial biológico de espécies de Fabaceae, especialmente devido a vasta importância econômica de seus exemplares (SANTOS et al., 2010; CRUZ, 2016). Anadenanthera colubrina apresenta potencial terapêutico reconhecido sendo amplamente utilizada pela medicina popular, trata-se de uma planta promissora, explorada do ponto de vista etnobotânico e econômico, mas ainda pouco explorada farmacologicamente (WEBER, 2011). A casca desta árvore é rica em taninos que conferem propriedades medicinais, tais como ação antiinflamatória, anti-oxidante e antimicrobiana (DESMARCHELIER et al., 1999; MONTEIRO et al., 2006). Já para o gênero Crotalaria, diversos são as aplicações de extratos de suas espécies, como para controle biológico (CARDOSO et al., 2006; GARRIDO et al., 2008, INOMOTO et al., 2008), fungos micorrízicos arbusculares (FILHO et al., 2000), fitoquímicos e em atividades farmacológicas (BARRETO et al., 2006).

Apesar da importância econômica indiscutível, espécies $A$. columbrina, l. vera e C. stipularia não apresentaram ação antibacteriana frente aos patógenos aqui testados, tal resultado pode ter sido influenciado pela adaptação da espécie a região de Divinópolis/MG, dentre outros fatores que podem contribuir para os diferentes resultados obtidos. Gonçalves (2005) também apontou para espécimes de $A$. columbrina como resistente à ação bactericida e ou bacteriostática, principalmente em relação a bactérias Gram-negativas, corroborando com os resultados obtidos neste trabalho. Sugere-se, deste modo, novos testes frente a outros microorganismos, além do teste com frações isoladas do extrato, uma vez que apresentam conteúdos fenólicos consideráveis, os quais pela literatura possuem conhecida atividade antimicrobiana.

Apesar de não encontrada nenhuma atividade antifúngica nos extratos etanólicos das espécies avaliadas neste trabalho, Schuch (2008) indicou que extratos de folhas de Bidens pilosa apresentaram ação antifúngica frente a espécies de fungos diferentes das aqui testadas, indicando a possibilidade de novos estudos com extratos desta espécie.

\section{CONCLUSÕES}

Os extratos vegetais obtidos neste trabalho, apresentaram ação antibacteriana classificados como bactericidas e ou bacteriostático, das 7 espécies de plantas analisadas 4 mostraram potencial bioativo, principalmente frente a bactérias Gram negativas. Além disso, essas espécies vegetais não apresentaram efeito antifúngico frente as leveduras testadas.

Neste sentido, nota-se que os resultados de atividades antimicrobianas observadas em extratos vegetais obtidos de espécies da região de Divinópolis/MG revelam a importância da prospecção de novos agentes antimicrobianos, eventualmente presentes na flora ainda inexplorada e encontrada em fragmentos de Cerrado e Mata Atlântica do interior do Brasil. Os efeitos bacteriostáticos e bactericidas dos extratos vegetais frente a bactérias de interesse clínico, aqui observados, revelam resultados de grande significância em uma realidade de crescimento de resistência bacteriana a antimicrobianos tradicionalmente utilizados. 
Neste contexto, abrem-se novas perspectivas quanto ao desenvolvimento de pesquisas com foco nestes achados tendo em vista que a descoberta de fontes naturais e ou desenvolvimento de fitoterápicos de fabricação nacional podem ter consequências econômicas significativas. Sob o ponto de vista ecológico a descoberta de fármacos de origem vegetal representa um forte argumento conservacionista. $\mathrm{O}$ valor econômico da preservação de plantas medicinais inclui diversos benefícios sociais, tais como atividades econômicas ligadas ao plantio, melhores condições de assistência à saúde, surgimento de novos modelos para a síntese de fármacos, novos compostos ativos contra microorganismos resistentes, além dos benefícios ambientais pela preservação de diferentes ecossistemas.

\section{REFERÊNCIAS}

ALVES, T. M. A.; SILVA, A. F; BRANDÃO, M.; GRANDI, T. S. M.; SMÂNIA, E. F. A.; JÚNIOR, A. S.; ZANI, C. L.. Biological Screening of Brazilian Medicinal Plants. Memórias do Instituto Oswaldo Cruz, Belo Horizonte, v.95, n.3, p.367-73, 2000.

AURICCHIO, M. T.; BACCHI, E. M.. Folhas de Eugenia uniflora L. (pitanga): propriedades farmacobotânicas, químicas e farmacológicas. Rev. Inst. Adolfo Lutz, São Paulo, v.62, n.1, p.55-61, 2003.

ANVISA. Agência Nacional de Vigilância Sanitária. Relatório de Atividades 2010: Agência Nacional de Vigilância Sanitária. Brasília: Anvisa, 2011.

ASHAFA, A. O. T.; AFOLAYAN, A. J.. Screening the root extracts from Bidens pilosa L. var. radiata (Asteraceae) for anti-microbial potentials. J. Med. Plants Res., Cabo city, v.3, n.8, p.568-572, 2009.

BARROS, L. M. B.; BENTO, J. N. C.; CAETANO, J. A.; MOREIRA, R. A. N.; PEREIRA, F. G. F.; FROTA, N. M.; ARAÚJO, T. M.; SOARES, E.. Prevalência de micro-organismo e sensibilidade antimicrobiana de infecções hospitalares em unidade de terapia intensiva de hospital público no Brasil. Rev. Ciênc. Farm. Básica, Fortaleza, v.33, n.3, p.429-435, 2012.

BARRETO, R. A.; HUGHES, J. B.; SOUZA; C. S.; SILVA, V. D. A.; SILVA, A. R.; VELOZO, E. S.; BATATINHA, M. J. M.; COSTA, M. F. D.; EL-BACHÁ, R. S.; COSTA, S. L.. O alcalóide monocrotalina, extraído de Crotalaria retusa, altera a expressão de GFAP, a morfologia e o crescimento de culturas primárias de astrócitos. Rev. bras. Saúde Prod. Anim., Fortaleza, v.7, n.2, p.112-127, 2006.

BAUER, A. W.; KIRBY, W. M. M.; SHERRIS, J. C.; TURCK, M.. Antibioticsusceptibility testing by a standardized single disc method. Am J Clin Pathol, v.45, n.4, p.493-496, 1966.

BOTSARIS, A.. Cresce o interesse pela fitoterapia: Medicina Ecológica. Rio de Janeiro: Nova Era, 2010.

BRASIL. Ministério da Saúde. Secretaria de Ciência, Tecnologia e Insumos Estratégicos. Departamento de Assistência Farmacêutica e Insumos Estratégicos. Política Nacional de Plantas Medicinais e Fitoterápicos. Brasília: Ministério da Saúde, 2006.
BURT, S.. Essential oils: their antibacterial properties and potential applications in foods: a review. Int J Food Microbiol, Utrecht, v.94, p.223-253,2004.

CABRAL, L. M. B.. Introduction to Industrial Organization, Massachusetts Institute of Technology Press, New York, v.1, n.2, p.223, 2000.

CARDOSO, S. C.; SOARES, A. C. F.; BRITO, A. S.; LARANJEIRA, F. F.; LEDO, C. A. S.; \& SANTOS, A. P.. Controle da murcha bacteriana do tomateiro pela incorporação da parte aérea de guandu e crotalária no solo. Summa Phytopathologica, Botucatu, v.32, n.1, p.27-33, 2006.

CLSI. Clinical and Laboratory Standards Institute. CLSI document M07-A9: Methods for Dilution Antimicrobial Susceptibility Tests for Bacteria That Grow Aerobically; Approved Standard. 9 ed. Pennsylvania: CLSI, 2012.

COUTO, R. O.; VALGAS, A. B.; BARA, M. T. F.; PAULA, J. R.. Caracterização Físico-Química do pó das folhas de Eugenia dysenterica DC. (MYRTACEAE). Revista Eletrônica de Farmácia, Goiânia, v.6, n.3, p.59-69, 2009.

CRUZ, S. A. B.. Avaliação da atividade tóxica e do perfil fitoquímico de duas espécies da família fabaceae: Bowdichia virgilioides kunth e Pterodon emarginatus Vogel. Anápolis: IFG, 2016.

DEBA, F.; XUAN, T. D.; YASUDA, M.; TAWATA, S.. Chemical composition and anti-oxidant, anti-bacterial and anti-fungal activities of the essential oils from Bidens pilosa Linn.var. radiata. Food Control, Tóquio, v.19, n.4, p.346-352. 2008.

DESMARCHELIER, C.; ROMÃO, R. L.; COUSSIO, J.; CICCIA, G. Antioxidant and free radical scavenging activities in extracts from medicinal trees used in the 'caatinga' region of northeastern Brazil. J Ethnopharmacol, v.67, n.1, p.69-77, 1999.

FENNER, R.; BETTI, A.H.; MENTZ, L. A.; RATES, S. M. K.. Plantas utilizadas na medicina popular brasileira com potencial atividade antifúngica. Rev. Bras. Cienc. Farm. Porto Alegre, v.42, n.3, 2006.

FILHO, A. C.; CARDOSO, E. J. B. N.. Detecção de fungos micorrízicos arbusculares em raízes de cafeeiro e de crotalária cultivada na entrelinha. Pesq. Agropec. Bras., v.35, n.10, p.2033-2042, 2000. 
FONSECA, S. G. C.; BRAGA, R. M. C.; SANTANA, D. P.. Lapachol - química, farmacologia e métodos de dosagem. Rev Bras Farmacogn, Fortaleza, v.84, n.9, p.16, 2003.

FRANCA, I. S. X.; SOUZA, J. A.; BAPTISTA, R. S.; BRITTO, V. R. S.. Medicina popular: benefícios e malefícios das plantas medicinais. Rev. bras. Enferm, Campina Grande, v.61, n.2, p.201-208, 2008

GARRIDO, M. S.; SOARES, A. C. F.; COIMBRA, J. L.; SOUSA, C. S.. Manejo da crotalária e do guandu no controle de nematoses do inhame. Summa Phytopathologica, Barreiras, v.34, n.3, p.222-227, 2008.

GUARIM NETO, G.. O saber tradicional pantaneiro: as plantas medicinais e a educação ambiental. Rev. eletrônica Mestr. Educ. Ambient., Rio Grande, v.17, n.3, p.38-46, 2006.

GONÇALVES, A. L.; FILHO, A. A.; MENEZES, H.. Estudo Comparativo Da Atividade Antimicrobiana De Extratos De Algumas Árvores Nativas. Arquivos do Instituto Biológico, v.72, n.3, p.353-358, 2005

HALBERSTEIN, R. A.. Medicinal Plants: Historical and Cross Cultural. Usage Patterns. Medicinal Plant Usage. Miami, v. 15, n.9, p.686-699, 2005.

HUGHES, C.; MULLER, D.; HACHER, J.; GOEBEL, W.. Genetics and pathogenic role of Escherichia coli haemolysin. Toxicon, Berlim, v.20, n.1, p.247-52, 1982.

IGNOATO, M. C.. Estudo fitoquímico e avaliação da atividade anti-inflamatória de Aeschynomene fluminensis vell. (Fabaceae). Química Nova, Maringá, v.35, n.11, p.22412244, 2012.

INOMOTO, M. M.; ANTEDOMÊNICO, S. R.; SANTOS, V. P.; SILVA, R. A.; ALMEIDA, G. C.. Avaliação em casa de vegetação do uso do sorgo, milheto e crotalária no manejo de Meloidogyne javanica. Tropical Plant Pathology, São Paulo, v.33, n.2, p.125-129, 2008

KHAN, M. R.; KIHARA, M.; OMOLOSO, A. D.. Antimicrobialactivity of Bidens pilosa, Bischofia javanica, Elmellia papuana and Sigesbekia orientalis. Fitoterapia, Papua New Guinea, v.72, n.6, p.662-665. 2001.

KRINSKI, D.; MASSAROLI, A.; MACHADO, M.. Potencial inseticida de plantas da família Annonaceae. Rev. Bras. Frutic, Botucatu, v.36, n.1, 2014.

LIMA, O. G.. Substâncias antimicrobianas de plantas superiores. Comunicação XIV. Ocorrência de antibióticos em madeiras de lei do Brasil. Rev Inst Antibiot, Recife, v.2, p.1933, 1959.

LIMA, M. R. F.; XIMENES, C. P. A.; LUNA, J. S.; SANTANA, A. E. G.. The antibiotic activity of some Brazilian medicinal plants. Rev Bras Farmacogn, Alagoas, v.16, n.3, p.300-306, 2006.

LYU, Y.; YANG, Y.; LYU, X.; DONG, N.; SHAN, A.. Antimicrobial activity, improved cell selectivity and mode of action of short PMAP-36-derived peptides against bacteria and Candida. Sci Rep, Pequim, v.6, n.2, p.1-12, 2016.
MARKHAM, K. P.. Techniques of flavonoid identification. London: Academic Press, 1982.

MING, L. C.; ALMEIDA, C. I. M.; MARQUES, M. O. M.; CONCEIÇÃO, D. M.; YUHARA T. Y.; LEONEL, S.; TAVARES, R. C.; SILVA, J.. The effect of bordaleza and sulfocálcica syrups in differentconcentrations and ages of plants on leafs diseases of sweetpassion fruit in organic cropping. Biotec. Biodivers. Gurupi, v.3, n.2, p.30-35, 2012.

MONTEIRO, J. M.; ALBUQUERQUE, U. P.; LINS-NETO, E. M. F.; ARAÚJO, E. L.; AMORIN, E. L. C.. Use patterns and knowledge of medicinal species among two rural communities in Brazil's semi-arid northeastern region. J Ethnopharmacol, Recife, v.105, n.1-2, p.173-186, 2006.

NCCLS. National Committee for Clinical Laboratory Standards. NCCLS document M27: Método de Referência para Testes de Diluição em Caldo para a Determinação da Sensibilidade a Terapia Antifúngica das Leveduras. Pennsylvania, 2002.

NCCLS. National Committee for Clinical Laboratory Standards. Methods forDetermining Bactericidal Activity of Antimicrobial Agents. Villanova: Order from NCCLA, 2006.

OMS. Organização Mundial da Saúde. Declaração De AlmaAta. In: CONFERÊNCIA INTERNACIONAL SOBRE CUIDADOS PRIMÁRIOS DE SAÚDE, 1. Anais. Alma-Ata: OMS, 1978. p.3.

O'NEILL, J.. Tackling Drug-Resistant Infections Globally: final report and recommendations. Review on Antimicrobial Resistance. New York, 2016.

RABE, T.; VON STADEN J.. Antibacterial activity of South Africa plants used for medicinal purposes. $J$ Ethnopharmacol, South Africa, v.56, n.1, p.81-87, 1997.

RAZAFINTSALAMA, V. E.; RASOARIVELO, S. T.; RANDRIAMIALINORO, R. F.; RANARIVELO, L.; RAKOTONANDRASANA, S. R.; PETIT, T.; SARTER, S. Antibacterial activities of fourteen medicinal plants from the endemic plant diversity of Madagascar. S. Afr. J. Bot, Madagascar, v.112, n.4, p.303-306, 2017.

ROCHA, E. A. L. S. S.; CARVALHO, A. V. O. R.; ANDRADE, S. R. A.; MEDEIROS, A. C. D.; TROVÃO, D. M. B. M.; COSTA, E. M. M. B.. Potencial antimicrobiano de seis plantas do semiárido paraibano contra bactérias relacionadas à infecção endodôntica. Rev. Ciênc. Farm. Básica Apl., Campina Grande, v.34, n.3, p.351-355, 2013.

SAKAGAMI, Y.; KAJAMURA, K.. Bactericidal activities of desinfectants against vancomycin-resistant Enterococci. J Hosp Infect, Tóquio, v.50, n.2, p.140-144, 2006.

SANCHEZ-VELAZQUEZ, L. D.; ROSALES, S. P. L.; FAUSTO, M. S. R.. The Burden of Nosocomial Infection in the Intensive Care Unit: Effects on Organ Failure, Mortality and Costs. A Nested Case-Control Study. Arch Med Res, México City, v.37, n.3, p.370-5, 2006

SANTANA, C. F.; LIMA, O. G.; DALBUQUERQUE, I. L.; LACERDA, A. L.. Observações sobre as propriedades antitumorais e toxicológicas do extrato do líber e de alguns componentes do cerne do Pau dárco (Tabebuia 
avellanedae). Rev Inst Antibiot, Recife, v.8, n.2, p.89-94, 1968.

SANTOS, R. F. E. P.; CONSERVA, L. M.; BASTOS, M. L. A.; CAMPESATTO, E. A.. Avaliação do potencial biológico da Tabebuia aurea (Silva Manso) como fonte de moléculas bioativas para atividade antimicrobiana, antiedematogênica e antirradicular. Rev. Bras. PI. Med., Botucatu, v.17, n.4, p.1159-1168, 2015.

SANTOS, A. P.; ZATTA, D. T.; MORAES, W. F.; BARA, M. T. F.; FERRI, P. H.; SILVA, M. R. R.; PAULA, J. R.. Composição química, atividade antimicrobiana do óleo essencial e ocorrência de esteróides nas folhas de Pterodon emarginatus Vogel, Fabaceae. Rev Bras Farmacogn, Goiânia, v.20, n.6, 2010.

SCHELZ, Z. M. J.; HOHMANN, J.. Antimicrobial and antiplasmid activities of essential oils. Phytotherapy, Budapeste, v.77, p.279-285, 2006.

SCHUCH, L. F. D.; WIEST, J. M.; GARCIA, É. N.; PRESTES, L. S.; SCHRAMM, R. C.; COIMBRA, H.; MEIRELES M. C. A.. Atividade antifúngica de extratos de plantas utilizados por agricultores familiares como antimicrobiano. Or agricultores familiares. Acta Sci Vet., Porto Alegre, v.36, n.3, p.267-271, 2008.
SHADOMY, S.; SPINEL-INGROF, A.. Susceptibility testing: with antifungal drugs. In: LENNETTE, E.. Manual of clinical of microbiology. 3 ed. Olympia: American Society for Microbiology, 1980. p.647-653.

SIMÕES, C. M. O.; MENTZ, L. A.; SCHENKEL, E. P.; NICOLAU, M.; BETTEGA, J. R.. Plantas da Medicina Popular do Rio Grande do Sul. Editora da UFRGS, Porto Alegre, v.1, n.5, p.150, 1998

SILVA, K. O.. Avaliação da atividade biológica de Anadenanthera macrocarpa (Benth) Brenan. Dissertação (Mestrado) -Universidade Federal da Bahia, Vitória da Conquista, 2011.

WEBER, C. R.; SOARES, C. M. L.; LOPES, A. B. D.; SILVA, T. S.; NASCIMENTO, M. S.; XIMENES, E. C. P. A.. Anadenanthera colubrina: um estudo do potencial terapêutico. Rev Bras Farmacogn, Recife, v.92, n.4, p.235-244, 2011.

WHO. World Health Organization. Antimicrobial resistance: Global report on surveillance. Geneva: World Health Organization, 2014.

A CBPC - Companhia Brasileira de Produção Científica (CNPJ: 11.221.422/0001-03) detém os direitos materiais desta publicação. Os direitos referem-se à publicação do trabalho em qualquer parte do mundo, incluindo os direitos às renovações, expansões e disseminações da contribuição, bem como outros direitos subsidiários. Todos os trabalhos publicados eletronicamente poderão posteriormente ser publicados em coletâneas impressas sob coordenação da Sustenere Publishing, da Companhia Brasileira de Produção Científica e seus parceiros autorizados. Os (as) autores (as) preservam os direitos autorais, mas não têm permissão para a publicação da contribuição em outro meio, impresso ou digital, em português ou em tradução. 